\title{
COMPARING THE EFFICACY OF ALOE VERA GEL VERSUS FERRIC SULPHATE AS A PULP MEDI- CAMENT IN VITAL PULPOTOMY OF DECIDUOUS MOLARS: A RANDOMIZED CONTROLLED TRIAL
}

\author{
Hassan Maqbool',2凶, Muhammad Aizaz Ali', \\ Umair UI Haq', Shahzad Ali Shah'
}

\begin{abstract}
OBJECTIVE: To compare the efficacy of Aloe vera (AV) gel versus Ferric Sulphate (FS) as a pulp medicament in vital pulpotomy of deciduous molars.

METHODS: This randomized controlled trial was conducted at Peshawar Dental College, Peshawar, Pakistan. One hundred and fourteen patients were randomized into interventional group $(\mathrm{A})$ : who received $\mathrm{AV}$ gel \& control group (B): who received FS as pulpotomy medicament. Deciduous molars of patients of both genders were selected for this study. Clinical signs \& symptoms and radiological findings were observed in both groups after a period of 6 months and then checked for their comparative efficacy.
\end{abstract}

RESULTS: Out of I I 4 patients, 69 (60.5\%) were males. Postoperative pain was reported be as no pain $[\mathrm{AV}=44 / 57(77.2 \%) ; \mathrm{FS}=43 / 57(75.4 \%)]$, mild pain $[\mathrm{AV}=07 / 57$ (I2.3\%); $\mathrm{FS}=\mathrm{I} \mathrm{I} / 57$ (19.3\%)], moderate pain $[\mathrm{AV}=03 / 57(5.3 \%)$; $\mathrm{FS}=0 \mathrm{I} / 57(\mathrm{I} .8 \%)]$ and severe pain $[\mathrm{AV}=03 / 57(5.3 \%) ; \mathrm{FS}=02 / 57(3.5 \%)]$ Periapical abscess was observed in total of 04/I I 4 (3.5\%) patients (AV=03/57; $\mathrm{FS}=0 \mathrm{I} / 57)$. Pathological tooth mobility was also present as mild/normal $[\mathrm{AV}=52 / 57$ (9l.2\%); $\mathrm{FS}=56 / 57(98.2 \%)]$, moderate $[\mathrm{AV}=04 / 57(7 \%)$; $\mathrm{FS}=0 \mathrm{I} / 57(\mathrm{I} .8 \%)]$ and severe $[\mathrm{AV}=0 \mathrm{I} / 57(\mathrm{I} .8 \%)]$. Radiographic changes were found in total of $06 / \mathrm{I} \mid 4(5.3 \%)$ patients $(\mathrm{AV}=04 / 57 ; \mathrm{FS}=02 / 57)$. Out of II4 patients, $51 / 57(89.47 \%$ ) cases remained successful in group $A$ while in group $B$, $54 / 57(94.73 \%)$ were successful.

CONCLUSION: AV tends to prove favorable outcomes in terms of clinical signs and symptoms and radiological features comparable to ferric sulphate and could be a better \& cheap alternative to other medicaments in future and can be used safely for pulpotomy.

KEY WORDS: Aloe Vera Gel (MeSH); Ferric Sulphate (MeSH); Pulpotomy (MeSH); Tooth (MeSH); Tooth, Deciduous (MeSH); Tooth Mobility (MeSH); Tooth Mobility Index (Non-MeSH); Periapical Abscess (MeSH); Pain (MeSH); Pain Measurement (MeSH); Visual Analog Pain Scale (MeSH).

THIS ARTICLE MAY BE CITED AS: Maqbool H, Ali MA, Haq UU, Shah SA. Comparing the efficacy of Aloe vera gel versus ferric sulphate as a pulp medicament in vital pulpotomy of deciduous molars: a randomized controlled trial. Khyber Med Univ J 2020; I2(I): I0-I4. DOI: I0.35845/kmuj.2020.1939I.

\section{INTRODUCTION}

\section{$\mathrm{V}$} ital pulpotomy is a procedure involving deciduous teeth, which involves removal of pulp from its chamber, thus trying to maintain the vitality of radicular pulp by using a pulp medicament.' The importance of vital pulpotomy is such that it is performed worldwide to conserve deciduous teeth from infection and premature loss. Various materials have been used as vital pulpotomy medicaments with their merits and demerits. ${ }^{2}$
I. Department of Operative Dentistry, Peshawar Dental College, Peshawar, Pakistan.

2. Department of Operative Dentistry, Khyber Medical University Institute of Dental Sciences (KMU-IDS), Kohat, Pakistan.

Email ${ }^{\Downarrow}$ :dr.hmaqbool@gmail.com Contact \# : +92-345-9178419

$\begin{array}{ll}\text { Date Submitted: } & \text { June 16,2019 } \\ \text { Date Revised: } & \text { February 25, 2020 } \\ \text { Date Accepted: } & \text { February 27, 2020 }\end{array}$

Ferric sulphate is the most commonly used pulp medicament nowadays which is non-aldehyde and a hemostatic agent the mechanism of which is to cause agglutination of proteins by forming a metal-protein clot with blood thereby occluding capillaries and thus causes reduced inflammation and less internal resorption. ${ }^{3}$ There are many studies which prove ferric sulphate as a superior vital pulpotomy medicament with least demerits thus reaching almost to gold standard. ${ }^{4-6}$ In a study conducted by Yadav P, et al. ferric sulphate was used in vital pulpotomy of deciduous molars including 45 patients. A success rate of $86.6 \%$ and $80 \%$ was calculated clinically and radiographically, respectively over a period of 9 months. ${ }^{6}$ In a similar study comprising 36 months follow up on 107 patients, Huth KC, et al. calculated a success rate of $76 \%$, both clinically and radiographically by using ferric sulphate. ${ }^{5}$

Recently, natural products are being employed in various disciplines of dentistry. ${ }^{7}$ One of them is Aloe vera, which is a Herbal Panacea. ${ }^{8}$ The gel from its leaves has been used in endodontics.' It is being employed as a pulp medicament in vital pulpotomy nowadays. $^{10,11}$ It is shown to have healing, inductive, anti-inflammatory and antibacterial properties. The gel derived from it contains acetylated glucomannan which has antiinflammatory properties thus suppressing inflammation and promoting healing. ${ }^{11-13}$ There are many studies which relate the use of Aloe vera in dentistry, but very limited studies include its use in vital pulpotomy procedures. $^{11,12}$ According to a study conducted on 15 patients by Gupta N 
Total patients eligible for study fulfilling the inclusion criteria $(n=\mid 30)$

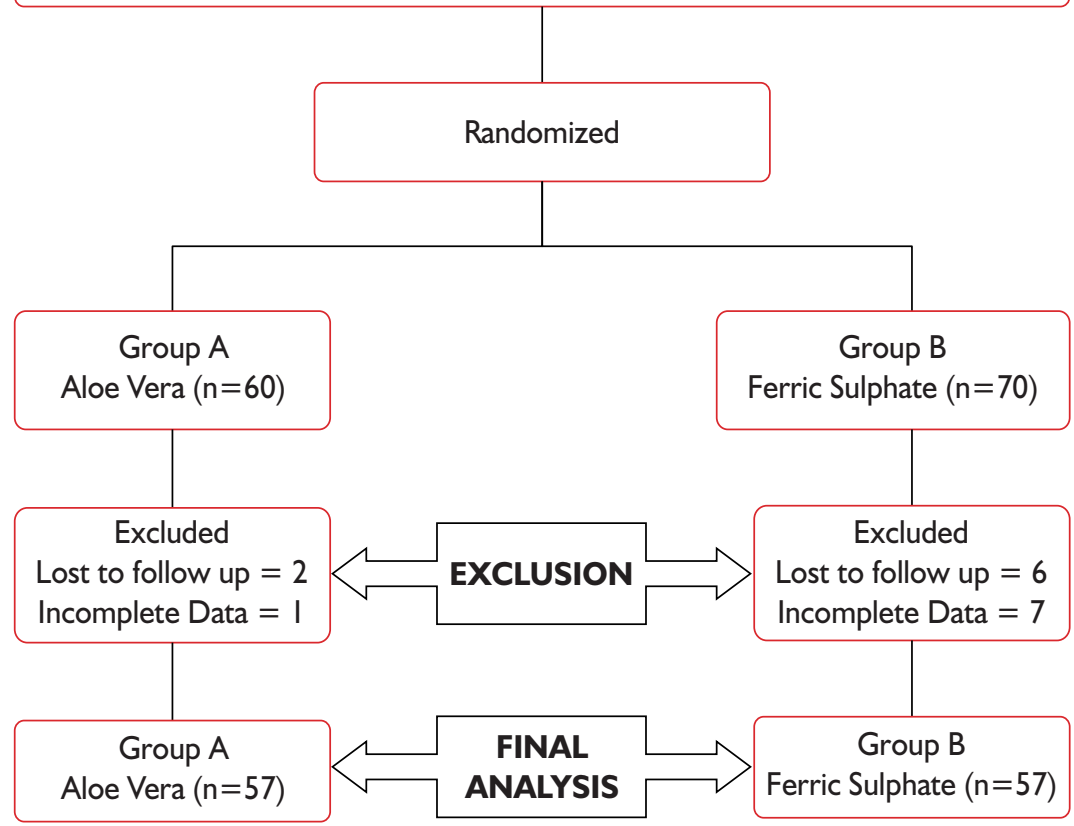

Figure I: Methodology flowchart for enrolment of subjects in both groups

et al. over a follow up period of 3 months, it was shown that Aloe vera gel is an effective pulp medicament with a success rate of $95 \%$ that promotes pulp healing with no radiographic and clinical symptoms at all after treatment." In another study conducted by Jittapiromsak $\mathrm{N}$, et al. primary human pulp tissues were exposed to Aloe vera gel and it was shown over a period of one month that Aloe vera promotes healing and is biocompatible, antiinflammatory, inductive and an effective vital pulpotomy medicament. ${ }^{12}$

The rationale of this study is based on the fact that although Aloe vera gel is a potent anti-inflammatory agent with the ability of wound healing but it is not clearly established whether it can be used successfully in vital pulpotomy as a pulp medicament. Also there is a lack of this study in local population. Aloe vera gel is biocompatible, regenerative and promotes healing. ${ }^{11-13}$ It is cheap, easily available and can be used safely with its anti-inflammatory properties. ${ }^{12,13}$ Unlike it, ferric sulphate is only a hemostatic agent which causes inflammatory response with treatment failures in long term studies and also it completely lacks inductive and healing properties. ${ }^{2-6}$ So this study will help to find out which material could be more effective in terms of its post-operative clinical signs \& symptoms and radiographic findings afterwards.

\section{METHODS}

This randomized controlled trial was conducted in Peshawar Dental College, Peshawar, Pakistan after taking prior permission from department of Operative Dentistry \& ethical review committee of Peshawar Dental College. The study duration was 6 months from April 2016 to September 2016.

All the children of any gender from age 4 to 9 years having vital tooth with healthy periodontium, absence of spontaneous and persistent pain and easily restorable tooth with easy control of bleeding from chamber were included in the study, while presence of internal resorption, periapical or inter radicular radiolucency, existence of sinus/abscess associated with diseased tooth, caries perforating the chamber floor, and tooth with resorbed roots which are near to shedding were excluded.

One hundred and thirty ( 75 male and 55 female) eligible patients were recruited in study and were randomized by flipcoin method into two groups, $A$ and $B$. Group-A included 60 and Group B had 70 patients. In group-A, three patients were excluded from final analysis (incomplete data $=I$ patient; lost to follow-up $=2$ patients). In group-B, thirteen patients were excluded from final analysis (incomplete data $=7$ patient; lost to follow-up $=6$ patients). So II4 patients were finally analysed with equal number of 57 patients in both group A\& B (Figure I).

History, clinical examination and preoperative periapical radiograph for selected mandibular and maxillary deciduous molars were taken in each patient. Patients were randomly allocated into 2 groups using coin flip method. After administering anesthesia, rubber dam was applied and access cavity was prepared. Coronal pulp was removed with excavator, chamber was washed with saline \& dried by cotton pellets. Aloe vera gel (FOREVER ALOE VERA GEL ${ }^{\mathrm{TM}}$ ) in interventional Group A while Ferric sulphate (I $5.5 \%)$ (Ultradent ${ }^{\circledR}$ ) was then used in control Group B as pulp medicament followed by placement of zinc oxide eugeno (kemdent ${ }^{\circledR}$ ) and then permanently restored with GIC cement $(G C \otimes)$ in both groups. Post treatment periapical radiographs were obtained. The data collected was strictly used for research purpose and was kept confidential.

Patients were then recalled after 6 months for follow up and to evaluate on basis of clinical signs \& symptoms, i.e. pain, periapical abscess \& pathological tooth mobility and radiographic findings. Postoperative pain was categorized into four groups using Visual Analogue Scale, i.e. no pain (0), mild (I-4), moderate (5-7) and severe $(>7)$. Pathological tooth mobility using Tooth Mobility Index was categorized into $\mathrm{mild} / \mathrm{normal}$ ( $\mathrm{lmm}$ ), moderate $(>1 \mathrm{~mm})$ and severe $(>2 \mathrm{~mm})$. Periapical abscess was observed as a swelling adjacent to offending tooth. Radiographic findings were noticed as periapical or inter radicular 
radiolucency upon periapical x-ray. The results were assessed \& charted down in a predesigned proforma.

The collected data was analyzed using SPSS version 25.0. Qualitative variables i.e., severity of pain, pathological tooth mobility, periapical abscess and radiographic findings, were calculated as frequency and percentages. While quantitative variables like age was calculated as Mean $\pm S D$. All the data will be presented in the form of tables and charts/graphs.

\section{RESULTS}

A total of II 4 patients were analyzed with equal number of 57 patients in each group. Out of these II 4 patients, $69(60.5 \%)$ were males and 45 (39.5\%) were females with male to female ratio was I.533:I. Patients included in the study had age range from 4-9 year with mean age was $6.62 \pm 1.478$. Age was stratified into three groups. Age group 4-5 year had $20 \%$ of the patients, group $>5-7$ years had $51 \%$ and group $>7-9$ years had $29 \%$ of patients.

Postoperative pain after 6 months follow up was categorized into four groups, i.e. no pain, mild, moderate and severe. Pain distribution according to categorization was overall $76.3 \%$, $15.8 \%, 3.5 \%$, and $4.4 \%$ respectively together in both groups. Those patients having pain were considered as unsuccessful cases. Periapical abscess (swelling) was observed after 6 months follow up overall in both groups together in $3.5 \%$ of patients (failure cases) while $96.5 \%$ of total sample had no abscess. Pathological tooth mobility was also observed after 6 months period and categorized as mild/normal (94.7\%), moderate $(4.4 \%)$ and severe $(0.9 \%)$. Moderate and severe tooth mobility were considered as unsuccessful cases. Radiographic changes were observed in few cases of total sample after 6 months period and was found be present in $5.3 \%$ (failure cases) while absent in $94.7 \%$ together in both groups. Out of 57 patients in group A (AV), out of 57 patients, $89.47 \%$ came out successful while $10.53 \%$ of patients were deemed failed. In Group B (FS), $94.73 \%$ of the cases were deemed successful while $5.26 \%$ of cases were remained a failure. These results were compiled on basis of presence \& absence of clinical signs/symptoms with radiographic findings respectively. Finally the efficacy between these two groups was measured, details of all variables after six months follow-up is presented in Table I.

\section{DISCUSSION}

In a recent study, the prevalence of pulpitis (toothache) was estimated to be about $14 \%$ in children of USA in the last 6 months, which makes about approximately 7.5 million. The prevalence was highest in children aged 6 to 12 years, with I in 7 affected by toothache. Among children, 32\% had experienced a recent pulpitis pain. Another finding was that poor and lowincome minority children were significantly more likely to have had pulpitis on multivariable analysis. ${ }^{14}$

Pulpitis is an endodontic emergency which needs to be treated by a safe and effective yet inexpensive therapy. Pulp capping, Pulpotomy and extracting the tooth are some modes of treatment normally given to patient.' Extraction is not a safe and effective option because of the fact that there are terrible consequences related to early loss of primary teeth in children. Pulp capping is a viable option but have higher failure rates so it is not indicated in children. Pulpotomy, however, is an effectively safe method to treat pulpitis while conserving the tooth as well with higher success rates in children. ${ }^{2}$

There are several medicaments used for pulpotomy. Among them, are Formocresol (FC) and glutaraldehyde which were meant to devitalize the pulp and are obsolete because of their systemic toxicity \& root resorptions. ${ }^{3}$ FS and lasers are hemostatic agents with better results in pulpotomy. FS although, considered to be the gold standard, it still causes internal resorptions in pulpotomized teeth and has failure rates in long term. ${ }^{4}$ Mineral Trioxide Aggregates (MTA) and biosilicates are revolutionary advancements in endodontics with highest success rates but because of the fact that MTA \& lasers are expensive and technique sensitive therefore cannot be commonly employed in pulpotomy. ${ }^{3,5,6}$

AV is one such herbal medicament which is effective, inexpensive and easily available. ${ }^{8}$ According to Gupta N, et al. " and Jittapiromsak $\mathrm{N}$, et al. ${ }^{12} \mathrm{AV}$ is biocompatible, inductive and

TABLE I: CROSS TABULATION OF DIFFERENT EFFICACY BASED VARIABLES IN STUDY GROUPS AFTER SIX MONTHS FOLLOW-UP

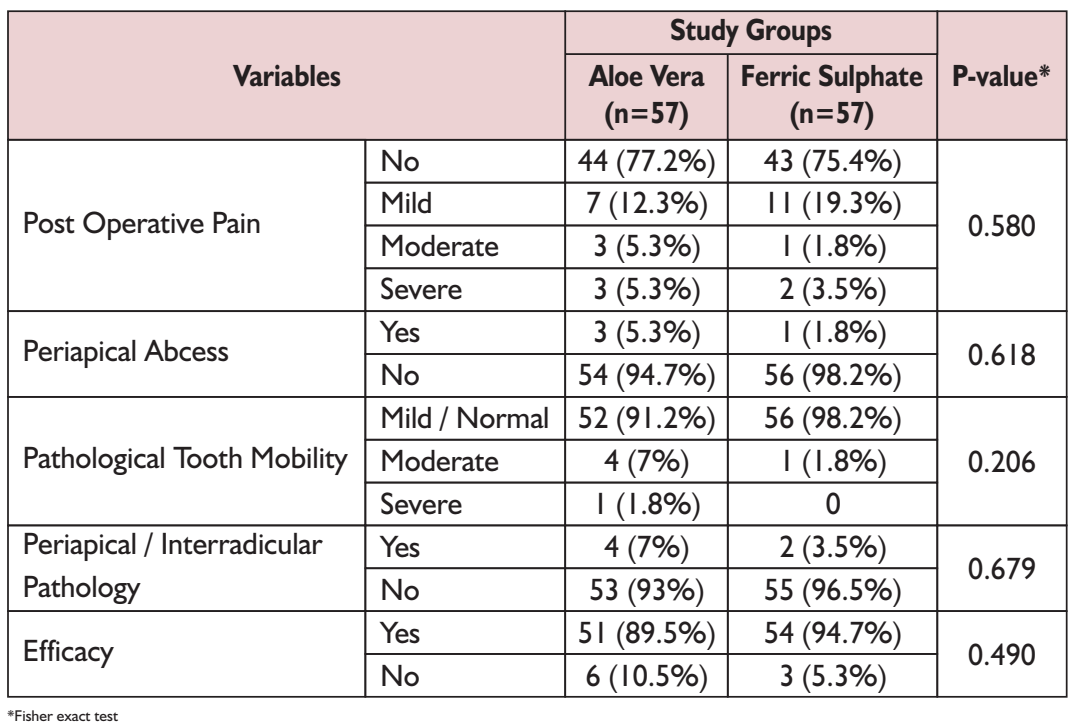


promotes healing of pulpal tissues. ${ }^{11-13}$ For all these reasons, $A V$ is selected for this study which proves to be quite promising in efficacy. In my study AV, although, has shown to be very effective pulpal medicament in pulpotomy, but results prove contrary to my hypothesis which said AV could be a better medicament and has become a null hypothesis so forth, therefore FS still proves to be a better medicament than AV.

The success rate of FS came out to be around $95 \%$, which is comparable to the study of Ibricevic $\mathrm{H}$, et al. ${ }^{15}$ In a local study by Khan AM, et al. ${ }^{16}$ the success rate of FS was $94 \%$ which is almost the same as this study. The success rate of $\mathrm{AV}$ is shown to be around $90 \%$ which is comparable to the study of Gupta $\mathrm{N}$ et al." In another international study by Gonna S, et al. ${ }^{17}$ success rate of AV came out to be $96.5 \%$ which can also relate to this study. Unfortunately, no local studies are available so more local studies with bigger sample size are needed.

This study might be having certain limitations. Although this is the best currently available evidence, the strength of clinical inference is not strong. Children are generally noncompliant patients. The history given by children are vague. Moreover, pain responses presented by children are not accurate which could lead to error. The inclusion \& exclusion criteria are such that sometimes teeth selected are partially necrosed presented with reversible pulpitis which are mistakenly selected. The limitation of sample size and duration of study could not happen to produce precise results. Moreover, children do not happen to present an organized pattern of follow up visits. All this suggests that the methodology might not be best designed, which incur risk of biases and ultimately effect conclusions overall. For this purpose more well-designed research studies are required. The use of $\mathrm{AV}$ in pulpotomy also require more clinical studies to validate its results.

\section{CONCLUSION}

Aloe vera gel tends to prove favorable outcomes in terms of clinical signs and symptoms and radiological features comparable to ferric sulphate and could be a better \& cheap alternative to other medicaments in future and can be used safely for pulpotomy and other endodontic procedures. Larger studies with robust methodology are needed to study the efficacy of Aloe vera as a pulp medicament.

\section{REFERENCES}

I. American Academy of Pediatric Dentistry, Clinical Affairs Committee-Pulp Therapy Subcommittee. Guideline on Pulp Therapy for Primary and Immature Permanent Teeth. Pediatr Dent 2016;38(6):280-88.

2. Rodd HD, Waterhouse PJ, Fuks AB, Fayle SA, Moffat MA; British Society of Paediatric Dentistry. Pulp therapy for primary molars. Int J Paediatr Dent 2006; I6(Suppl. I): I5-23. DOI: I0.IIII/j.I365263X.2006.00774.x.

3. Yildiz E, Tosun G. Evaluation of formocresol, calcium hydroxide, ferric sulfate, and MTA primary molar pulpotomies. Eur J Dent 20।4;8(2):234-40. DOI: I0.4103/ |305-7456. |306|6.

4. Smith NL, Seale NS, Nunn MS. Ferric sulfate pulpotomy in primary molars: a retrospective study. Pediatr Dent 2000;22(3): 192-9.

5. Huth KC, Hajek-Al-Khatar N, Wolf P, Ilie N, Hickel R, Paschos E. Longterm effectiveness of four pulpotomy techniques: 3-year randomized controlled trial. Clin Oral Investig 2012; I6(4): I 243-50. DOI: 10.1007/ s00784-0II-06023.

6. Yadav P, Indushekar KR, Saraf B, Sheoran N, Sardana D. Comparative evaluation of Ferric Sulfate, Electrosurgical and Diode Laser on human primary molars pulpotomy: an "in-vivo" study. Laser Ther 20I4;23(I):4I-7. DOI: I0.5978/islsm. I4-OR-05.

7. Taheri JB, Azimi S, Rafieian N, Zanjani HA. Herbs in dentistry. Int
Dent J 20II;6I(6):287-96. DOI: |0.। III/ j.|875-595X.20। I. 00064.x.

8. Wadhawan R, Khan SDAA, Solanki G, Sabir S. Aloe Vera: A Boon in Dentistry. Int J Pharm Rev Res (IJPRR) 20 | 4;4(3): |47-5 I .

9. Agarwal A, Dwivedi N. Aloe Vera: Magic or myth. SRM J Res Dent Sci 2013 ; 4(3): II9-24. DOI: $10.4103 / 0976-433 X .121638$.

10. Sundarkar P, Govindwar R, Nyamati S, Alladwar N, Thombre $V$, Soni $A$, et al. Use of aloe vera in dentistry. J Indian Acad Oral Med Radiol (JIAOMR) 201 I;23(5):3899I. DOI: 10.5005/jp-journalsI00II-II 77.

I I. Gupta N, Bhat M, Devi P, Girish. Aloe-Vera: A Nature's Gift to Children. Int J Clin Pediatr Dent 2010;3(2):87-92. DOI: 10.5005/jpjournals-10005-1059.

12. Jittapiromsak N, Sahawat D, Banlunara W, Sangvanich P, Thunyakitpisal P. Acemannan, an extracted product from Aloe Vera, stimulates dental pulp cell proliferation, differentiation, mineralization, and dentin formation. Tissue Eng Part A 20 I 0; I 6(6): I 997-2006. DOI: 10.1089/ten.TEA. 2009.0593.

13. Gala-Garcia A, Teixeira KI, Mendes LL, Sobrinho AP, Santos VR, Cortes ME. Effect of Aloe vera on Rat Pulp Tissue. Pharmaceutical Biol 2008;46(5):302-8. DOI: |0.1080/| 388020080|887| 38 .

14. Lewis C, Stout J. Toothache in US children. Arch Pediatr Adolesc Med 2010; I64(II): I059-63. DOI: I0.100 I /archpediatrics.2010.206.

15. Ibricevic H, Al-Jame Q. Ferric sulphate and formocresol in pulpotomy of primary molars: long term follow-up study. Eur J Paediatr Dent 2003;4(I):28-32.

16. Khan AM, Maxood A, Farani KS, Khan NA. Efficacy of Formocresol and Ferric Sulphate pulpotomies in Cariously Exposed Primary Molars. J Adv Med Dent Sci Res 


$$
\text { 20I8;6(I):I-6. }
$$

17. Gonna S, Ghoname N, Kabbash A. Efficacy of Aloe Vera as A Pulpotomy Agent in Children
Primary Teeth: Clinical and Radiographic Studies. J Gastroenterol Hepatol Res 20I9;8(5):2946-5I. DOI:
I $0.17554 /$ j.issn. 2224 3992.2019 .08 .842 .

\section{AUTHORS' CONTRIBUTIONS}

Following authors have made substantial contributions to the manuscript as under:

HM: Conception and study design, acquisition, analysis and interpretation of data, drafting the manuscript, critical review, final approval of the version to be published

MAA: Acquisition of data, drafting the manuscript, final approval of the version to be published

UUH: Analysis and interpretation of data, drafting the manuscript, final approval of the version to be published

SAS: Conception and study design, analysis and interpretation of data, critical review, final approval of the version to be published

Authors agree to be accountable for all aspects of the work in ensuring that questions related to the accuracy or integrity of any part of the work are appropriately investigated and resolved.

\begin{tabular}{|c|}
\hline CONFLICT OF INTEREST \\
Authors declared no conflict of interest \\
GRANT SUPPORT AND FINANCIAL DISCLOSURE \\
NIL
\end{tabular}

(cc) (i) (\$)

This is an Open Access article distributed under the terms of the Creative Commons Attribution-Non Commercial 2.0 Generic License.

KMUJ web address: www.kmuj.kmu.edu.pk

Email address: kmuj@kmu.edu.pk 